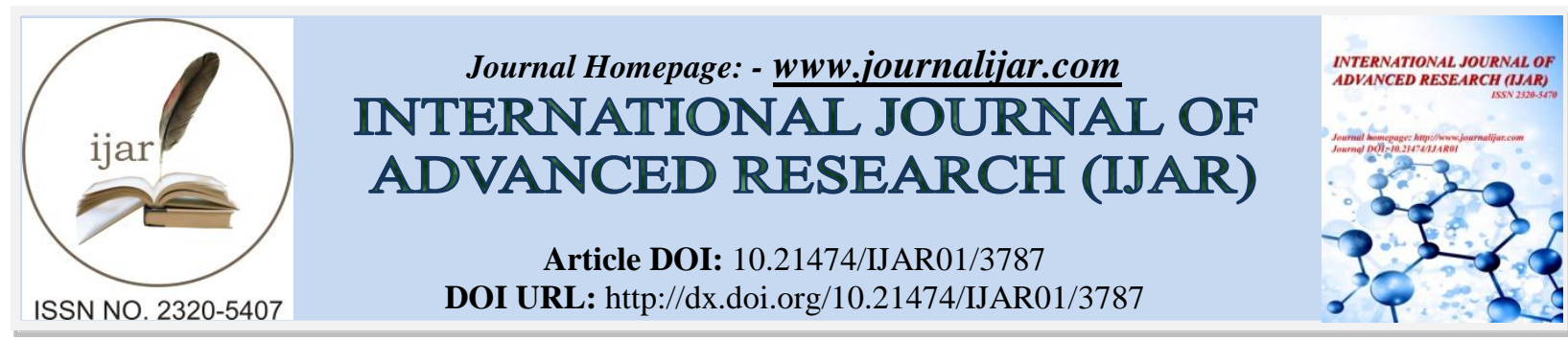

RESEARCH ARTICLE

\title{
ANALYSIS OF GENETIC STABILITY OF THE IN VITRO PROPAGATED ROSA DAMASCENA (TAIF ROSE) PLANT.
}

Hossam M. Zakaria ${ }^{2}$, Eldessoky S. Dessoky ${ }^{1,2}$, Ismail A. Ismail ${ }^{1,2}$, Attia O. Attia ${ }^{1,2}$, and Ehab I. El-Hallous ${ }^{1,3}$.

1. Biotechnology and Genetic Engineering Research Unit, Deanship of Scientific Research, Taif University, Taif, Al-Haweiah, P.O. Box 888, Zip code 21974, Taif, KSA.

2. Agricultural Genetic Engineering Research Institute, Agricultural Research Center, P.O. Box, 12619, Giza, Egypt.

3. Faculty of Science, Arish University, Al-Arish, Egypt.

\section{Manuscript Info}

Manuscript History

Received: 01 February 2017

Final Accepted: 04 March 2017

Published: April 2017

Key words:-

Genetic stability, Rosa damascena, RAPD analysis.

\section{Abstract}

Through optimization processes of plants by mass production using micropropagation or using genetic transformation, the most important aspect is to retain genetic integrity with reference to the mother plants. It is important to retain and improve the Taif rose (Rosa damascena) plant for its economic and medical importance. Although no or minor morphological variations were recorded in some micropropagated plants. In present study, Randomly Amplified Polymorphic DNA (RAPD) markers were employed to determine the genetic fidelity of Taif rose plantlets multiplied in vitro by using nodal segments. Among the screened 10 RAPD primers, were generated total of 801 clear, distinct and reproducible bands. Among these bands, 798 bands were monomorphic $(99.63 \%)$ and 3 bands were polymorphic $(0.37 \%)$. This very low polymorphism ratio between mother plants and micropropagated plantlets indicates the little effect of somaclonal variations and the high genetic similarity between mother plants and micropropagated plants. The molecular profiling by using RAPD markers proved to be an effective method and can be applied for assessing genetic stability of micropropagated plants. Thus, the developed in vitro plantlets which ascertained stability can be used successfully.

Copy Right, IJAR, 2017,. All rights reserved.

\section{Introduction}

Roses are the best popular garden plants in the world known as ornamental plants grown for their flowers and are used as cut flowers, potted plants, and garden plants and considered as the most important crops in the floriculture industry and they have been also used for commercial perfumery and commercial cut flower crops (Babaei et al. 2007; Nour El-Deen et al. 2015). The genus Rosa is a member of the family Rosaceae, in which more than 150 species were classified (Abdel-Hameed et al. 2013). There are more than 20,000 commercial cultivars, which collectively are based on only eight wild species (Kim \& Lieth 2003).

Taif is one of the oldest cities in the world and is known for its famous Wardh Taifi, the rose of Taif. It is located in the western part of Saudi Arabia, close to the holy city of Mecca and is placed about 2000 meters above sea level 
and in the time of the Ottoman Empire, this region was named the Arabian Rose, because roses began to be cultivated there. The governorate of Taif and its valleys, Hada, Al Shafa, Al Ghadeerayn and Wadi Mahram, are known for farming of this rose, which creates more income than the cultivation of other plants. Taif rose, Wardh Taifi (Rosa damascena trigintipetala) belongs to the species Damask Rose and considered as one of the most important economic products of Taif governorate, Saudi Arabia, which yields a highly fragrant commercially valuable essential oil. Roses of Taif have important role in the national economy for their great value in exportation of their oil to the Arab countries, medicinal use, ornamentation as well as manufacture of perfumes (Jalali-Heravi et al. 2008; El-Assal et al. 2014). The products of Al-Taif rose, beside rose oil, are rose water and dried petals that are used in medicine, perfume industry as well as make-up products (Nariman et al., 2011). Rose plants are propagated by seed, stem cutting, grafting, budding, cutting-graft (stenting), cutting-budding, grafting of root and tissue culture (Dole and Wilkins, 2005; Attia et al. 2012).

Given the economic and medical importance of Taif rose, it is important to cultivate the plant in a wide agriculture land to produce large quantities of it and this needs a wide agriculture area. For that purpose, the best way to produce these large quantities is the in vitro propagation of the rose and uses some protocols to produce genetically identical propagated plants to the mother plant. The evaluation of the genetic stability of in vitro derived clones is an important step in the application of biotechnology for micropropagation of true-to-type clones (Eshraghi et al., 2005, Ilczuk and Jacygrad 2016). The reliability and efficiency of molecular markers are frequently questioned. RAPD assay has been employed to test clonal fidelity because of their simplicity and cost effectiveness. The detection of genetic fidelity in tissue culture raised plant has been reported by many workers using RAPD markers (Rout and Das, 2002; Martins et al., 2004; Venkatachalam et al., 2007; El-Tarras et al., 2012; Goyal et al. 2015; Bakhshaie, et al. 2016).

In this study, the evaluation of genetic stability of the in vitro propagated Taif rose ( $R$. damascena) plants have been demonstrated using Random Amplified Polymorphic DNA (RAPD) technique.

\section{Materials and Methods}

\section{Materials of plants and Micro Propagation Protocol:-}

Stem nodal contains axillary buds was used for in vitro propagation according to the previous protocol (Attia et al. 2012). Briefly, nodal contains axillary buds of Taif rose (R. damascena) were collected from mature plants grown in Taif governorate, KSA. Nodal segments were cutting into appropriate sizes (1 to $1.5 \mathrm{~cm})$ after washing and sterilization of the source tissues and cultured on sterile basal MS medium gelled with 0.8\% (w/v) agar supplemented with $2 \mathrm{mg} / \mathrm{L} \mathrm{BAP}$ and $1 \mathrm{mg} / \mathrm{L} \mathrm{Kin.} \mathrm{Proliferation} \mathrm{of} \mathrm{axillary} \mathrm{buds} \mathrm{and} \mathrm{shoots} \mathrm{were} \mathrm{observed} \mathrm{after} \mathrm{two}$ weeks. For multiplication of shoots, the obtained shoots were sub-cultured at 4-week intervals on fresh medium with the same compositions. The proliferated shoot clusters after this period, were sub-cultured in MS medium supplemented with $3 \mathrm{mg} / \mathrm{L} \mathrm{BAP}$ and $1 \mathrm{mg} / \mathrm{L}$ kin for shoot elongation. For roots induction, in vitro micro-shoots (2 to $3 \mathrm{~cm}$ length) were excised aseptically and implanted on MS medium containing $3 \mathrm{mg} / \mathrm{L}$ IBA. All the cultures were incubated at $25 \pm 2{ }^{\circ} \mathrm{C}$ under a $16 \mathrm{~h}$ photoperiod and white fluorescent lamps (3000 lux). Plants with appropriate roots were transferred to pots containing a sterile soil and were acclimated in the green house. The complete procedures of in vitro propagation of Taif Rose (R.damascena) followed by acclimatization was presented in figure 1.

\section{Genomic DNA Isolation and Purification}

Genomic DNA was isolated from freshly young healthy leaves, that collected from the mother and in vitro propagated plants and powdered with liquid $\mathrm{N}_{2}$ by mortar and pestle using the procedure described by the plant isolation kit (Biospin Plant Genomic DNA Extraction Kit, Japan).

\section{RAPD Analysis:-}

Among the total of fourteen random primers that were used to detect the polymorphism, only ten primers were produced a clear sortable and reproducible banding pattern. The amplification reactions were performed in a $25 \mu 1$ reaction volume containing about $30 \mathrm{ng}$ genomic DNA, $2 \mathrm{mM}$ of each primers (Operon Technologies Inc.), $12.5 \mu \mathrm{l}$ of Promega master mix $(2 \mathrm{X})$ and the final volume was adjusted to $25 \mu \mathrm{L}$ with PCR water. The PCR reactions were applied using the Bio-Rad C1000 thermal cycler (Germany). An initial step for 5 min at $94^{\circ} \mathrm{C}$ was performed and followed by 40 cycles with conditions of an initial step for $1 \mathrm{~min}$ at $94^{\circ} \mathrm{C}$, an annealing step for $1 \mathrm{~min}$ at $37^{\circ} \mathrm{C}$ and an elongation step for $1 \mathrm{~min}$ at $72^{\circ} \mathrm{C}$; and finally an extension step for $7 \mathrm{~min}$ at $72^{\circ} \mathrm{C}$. The amplification products were analysed by electrophoresis in a $1.5 \%$ agarose gel containing ethidium bromide $(0.5 \mu \mathrm{g} / \mathrm{ml}) \mathrm{in} 1 \mathrm{X}$ TBE 
buffer at 95 volts. PCR products were visualized on UV light and photographed using a gel documentation system (Bio-Rad® Gel Doc-2000).

The produced amplified bands were detected by their primer code and their size in base pairs. Only intense and reproducible bands appearing on the gel were scored. Data recorded as discrete variables: the presence of band indicates with 1 and the absence of a similar band with zero. Band scoring was analyzed using Gene Tools-gel analysis software of SPSS ver.16.

\section{Results and Discussion}

In this investigation, the micropropagated plantlets have been found to be phenotypically normal and identical with the mother plant in the hardening phase suggest which partly minimal or no differences of somaclonal.

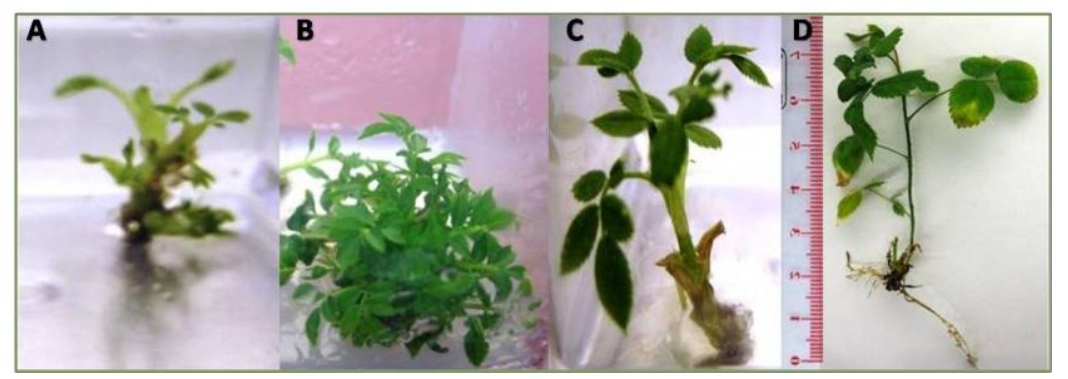

Figure 1: Stages of in vitro propagation of Taif Rose (Rosa damascena) plant.

Random amplified polymorphic DNA (RAPD) fingerprint technique used to assess the micropropagated Taif Rose (R. damascena) plants for genetic stability. Out of 14 screened primers of RAPD, ten primers produced resolvable, reproducible and scorable bands (table 1$)$.

Table 1:- Polymorphic bands of each genetic primers and percentage of polymorphism in micropropagated Taif Rose plantlets and mother plant by RAPD marker.

\begin{tabular}{|c|c|c|c|c|}
\hline Primers & Primers sequence & $\begin{array}{c}\text { Amplified } \\
\text { bands }\end{array}$ & Monomorphic bands & $\begin{array}{c}\text { Polymorphic } \\
\text { bands }\end{array}$ \\
\hline OP-A10 & 5' CAGGCCCTTC 3' $^{\prime}$ & 66 & 65 & 01 \\
\hline OP-A17 & 5' GACCGCTTGT 3' & 62 & 61 & 01 \\
\hline OP-A19 & $5^{\prime}$ CAAACGTCGG 3' & 60 & 60 & 00 \\
\hline OP-B2 & 5' TGATCCCTGG 3' $^{\prime}$ & 60 & 60 & 00 \\
\hline OP-B3 & 5' CATCCCCCTG 3' & 80 & 80 & 00 \\
\hline OP-B4 & 5'GGACTGGAGT 3' & 90 & 90 & 00 \\
\hline OP-B6 & 5'TGCTCTGCCC 3' & 90 & 90 & 00 \\
\hline OP-B9 & 5'TGGGGGACTC 3' & 143 & 143 & 00 \\
\hline OP-B11 & 5'GTAGACCCGT 3' & 80 & 80 & 00 \\
\hline OP-B12 & 5'CCTTGACGCA 3' & 70 & 69 & 01 \\
\hline Total & & 801 & 798 & $\mathbf{0 3}$ \\
\hline
\end{tabular}

Most of primers (7 of 10) used had a homogeneous amplification profile between the explant source and all the micropropagated plantlets. In RAPD analysis, ten primers produced 801 bands with $0.37 \%$ polymorphism ( 3 bands). These 3 polymorphic bands were produced by only 3 primers (30\%). The three primers OPA-10, OPA-17 and OPB12 produced 1 polymorphic band that represent $1.5,1.6 \%$ and $1.3 \%$ of the total bands produced by each primer, respectively. The other seven primers $(70 \%)$ showed $100 \%$ monomorphic pattern (The banding pattern produced by all primers are shown in figure 2). Number of bands produced by the ten primers was ranged between 6 and 13 with average of 9.5 bands per primers (Table 1). 

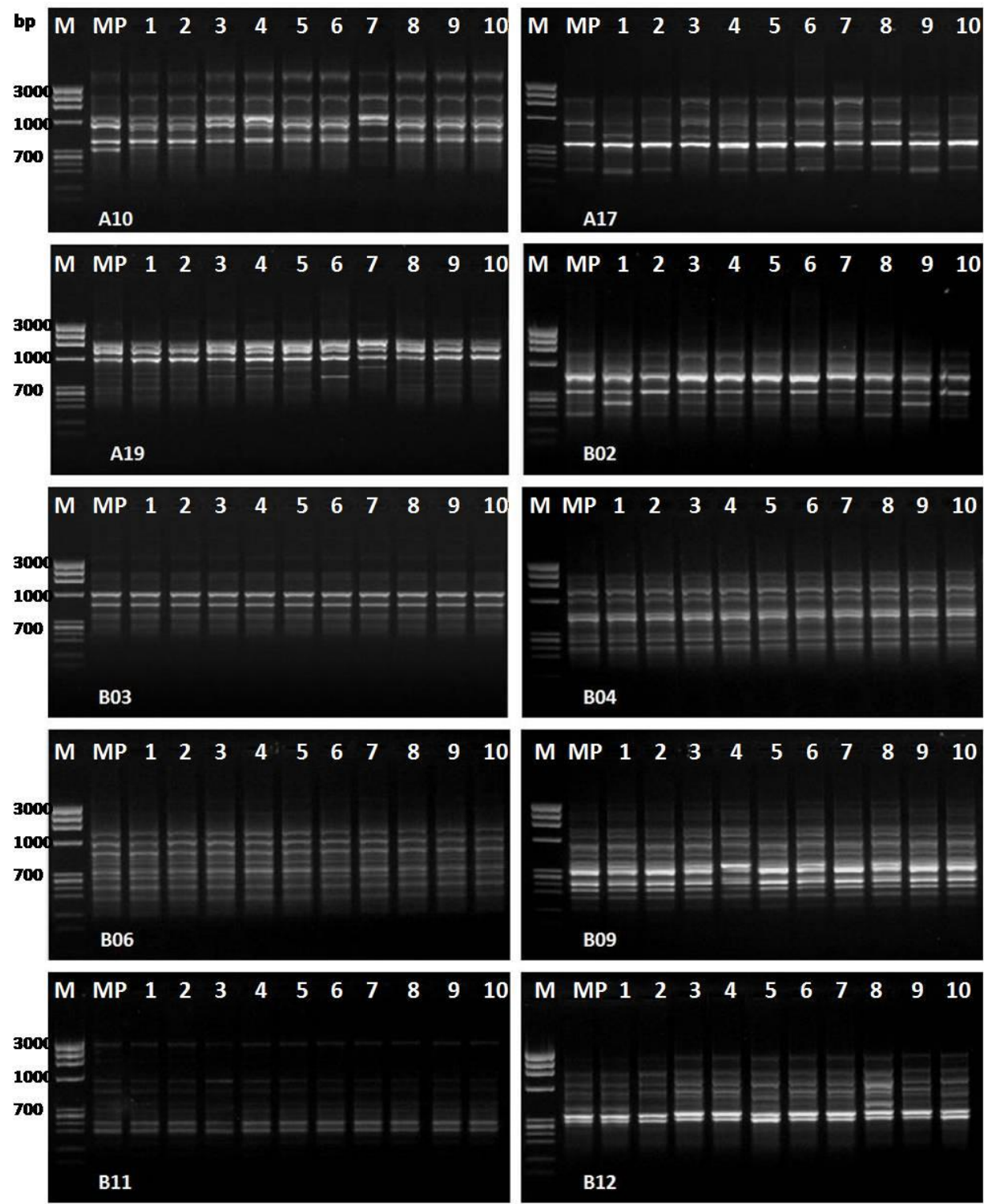

Figure 2: Amplification of genomic DNA from tissue culture derived plants of Taif Rose (R. damascena) by all primers used in this study. M corresponds to a 100 bp DNA ladder; MP represents mother plant serving as explants source.

The high ratio of monomorphic banding pattern in micropropagated and mother plants and the low frequency of polymorphism in RAPD of micropropagated plantlets suggesting the occurrence of little effects of somaclonal variations and confirms the high genetic homogeneity of the in vitro raised plants and also indicates that this micropropagation protocol is efficient enough to maintain genetic stability. These results agree with the results obtained previously, Srivastava et al. (2006), evaluated that, less than 6\% frequency polymorphism of in vitro raised sugarcane varieties produced from shoot-tip culture through RAPD markers. As similarities of 94.1-98.5\% and 97.299.0\% were recorded between the mother and micropropagated plants samples. Joshi and Dhawan (2007) have been confirmed that the plants of Swertia chirayita multiplied through axillary method of micropropagation maintain genetic fidelity even after prolonged period of 168 weeks under in vitro condition. Bhowmik et al. (2009) reported analysis of genetic uniformity using RAPD markers in micropropagated antisia spathulata. Genetic variation was also detected among in vitro regenerated garlic (Wang et al. (2016). The variation in the RAPD pattern can be explained as a result of the insertion/deletion of transposons and point mutation that cause the loss or gain of primer annealing sites (Peschke et al. 1991). 
Employing different marker systems helps in indication of the variation induced by genetic and epigenetic mechanism that likely to be reflected deferent banding profiles. The evaluated high genetic similarity of the micropropagated rose plants raised from nodal segments containing axillary buds with the mother plants in this study support the fact that the axillary multiplication is the safest mode of micropropagation to produce true to type progeny. There are many reports in literature reporting similar results (Rani and Raina, 2000; Carvlho et al., 2004; Martins et al., 2004; Joshi and Dhawan, 2007 and Bradshaw, 2017) which suggested that plants regenerated through organized tissues like meristems or direct somatic embryo-genesis maintain genetic integrity of the plantlets with less risk of genetic variation.

Palombi and Damiano (2002) suggested the use of more than one DNA amplification technique as advantageous in evaluating somaclonal variation while working on micropropagated plants of kiwi fruit.

In addition, the usages of two markers that amplify different regions of the genome allow better chances for the identification of genetic variations in the clones (Martins et al., 2004). We will be planning to confirm the genetic stability of the Taif Rose using another technique in the near future.

\section{Conclusion}

From the present study, the obtained results indicated good genetic fidelity obtained in the in vitro grown plantlets when examined by the RAPD system, a polymorphism rate of $<1 \%$ was detected by RAPD assay which may be due to point mutations occurring outside the priming sites. Hence we concluded that the protocol developed could be effectively used for rapid micropropagation and commercial utilization of Taif rose (Rosa damascene) without taking much risk of genetic instability. Thus, this method can be applied efficiently to determine the genetic purity of in vitro derived rose plantlets among tissue culture raised clones.

\section{References}

1. Abdel-Hameed, E., Bazaid, S. A. \& Salman, M. S. (2013). Characterization of the phytochemical constituents of Taif rose and its antioxidant and anticancer activities. Biomed.Res.Int., 345465, 1-13.

2. Attia, A. O., Dessoky, E. S. \& El-Tarras, A. E. (2012). In vitro propagation of Rosa hybrida L. cv. Al-Taif Rose plant. African Journal of Biotechnology, 11, 10888-10893.

3. Babaei, A., Tabaei-Aghdaei, S. R., Khosh-Khui, M., Omidbaigi, R., Naghavi, M. R., Esselink, G. D. \& Smulders, M. J. (2007). Microsatellite analysis of Damask rose (Rosa damascena Mill.) accessions from various regions in Iran reveals multiple genotypes. BMC. Plant Biol., 7, 12.

4. Bakhshaie, M., Khosravi, S., Azadi, P. Bagheri, H. and van Tuyl, J. M., (2016). Biotechnological advances in Lilium. Plant Cell Rep 35: 1799.

5. Bhowmik, S. S., Kumaria, S., Rao, S. R. \& Tandon, P. (2009). High frequency plantlet regeneration from rhizomatous buds in Mantisia spathulata Schult. and Mantisia wengeri Fischer and analysis of genetic uniformity using RAPD markers. Indian Journal of Experimental Biology, 47:140-146.

6. Bradshaw, J. E. (2017). Plant Breeding: Past, Present and Future. Euphytica 213: 60.

7. Carvlho, C., Zehr, U., Gunaratna, N., Andereson, J., Kononowicz H., Hodges T. \& Axtell J. (2004). Agrobacterium-mediated transformation of sorghum: factors that affect transformation efficiency. Genetics and Molecular Biology, 27:259-269.

8. Dole, J. M. \& Wilkins, H. F. (2005). Floriculture: principles and species. 2nd ed. Prentice Hall, Upper Saddle River, N.J. 558pp.

9. El-Assal, S. E., El-Awady, M. A., El-Tarras, A. \& Shehab, G. (2014). Assessing the genetic relationship of Taif rose with some rose genotypes (rosa sp.) based on random amplified polymorphic DNA, Inter Simple Sequence Repeat and Simple Sequence Repeat markers. American Journal of Biochemistry and Biotechnology, 10, 88-98.

10. El-Tarras, A., El-Awady, A. M., Attia, O. A. \& Dessoky, S. E. (2012). In vitro multiplication of the important medicinalplant, harmal (Rhazya stricta Decne). Journal of Medicinal Plants Research, 6(19): 35863590.

11. Eshraghi P., Zarghami R. \& Ofoghi H. (2005). Genetic stability of micropropagated plantlets in Date Palm. J.Sci., 16(4): 311-315.

12. Goyal, A. K., Pradhan, S., Basistha, B. C., \& Sen, A. (2015). Micropropagation and assessment of genetic fidelity of Dendrocalamus strictus (Roxb.) nees using RAPD and ISSR markers. 3 Biotech, 5(4), 473-482. 
13. Ilczuk, A. \& Jacygrad, E. (2016). In vitro propagation and assessment of genetic stability of acclimated plantlets of Cornus alba L. using RAPD and ISSR markers. In Vitro Cellular \& Developmental Biology - Plant, $52,(4), 379-390$.

14. Jalali-Heravi, M., Parastar, H. \& Sereshti, H. (2008). Development of a method for analysis of Iranian damask rose oil: combination of gas chromatography-mass spectrometry with Chemometric techniques. Anal.Chim.Acta, 623, 11-21.

15. Joshi, P., \& Dhawan, V. (2007). Assessment of genetic fidelity of micropropagated Swertia chirayita plantlets by ISSR marker assay. Biol. Plant, 51(1): 22-26.

16. Kim, S. H. \& Lieth, J. H. (2003). A coupled model of photosynthesis, stomatal conductance and transpiration for a rose leaf (Rosa hybrida L.). Ann.Bot., 91, 771-781.

17. Martins, M., Sarmento, D. \& Oliveira, M. M. (2004). Genetic stability of micropropagated almond plantlets, as assessed by RAPD and ISSR markers. Plant Cell Reports, 23(7):492-496.

18. Nariman, A., Salama, K. \& Abouseada, M. (2011). Improvement of production and quality of AL-Taif Rose via tissue culture techniques. Adv. Scholar Med., 1(3):22-25.

19. Nour El-Deen, A.H., El-Ghamdi, A. A., Samra, B. N. \& Hadeer, D. Y. (2015). Evaluating the pathogenicity of nematodes infecting roses at taif governorate, KSA. Research Journal of Pharmaceutical, Biological and Chemical Sciences, 6, 1562-1567.

20. Palombi, M. \& Damiano, V. (2002). Comparison between RAPD and SSR- molecular marker in detecting genetic variation in kiwi fruit (Actindia deliciosa A. Chev). Plant Cell Report, 20: 1061-1066.

21. Peschke, V. M., Phillips, R. L. \& Gengenbach, B.G (1991). Genetic and molecular analysis of tissue culture derived Ac elements. Theoret. Appl. Genet., 82: 121-12.

22. Rani, V. \&Raina, S. N. (2000). Genetic fidelity of organized meristem derived micropropagated plants: a critical reappraisal. In vitro Cell Dev Biol Plant, 36:319-330.

23. Rout, G. R. \& Das, P. (2002). In vitro studies of ginger: A review of recent progress. In Recent Progress in Medicinal Plants, Biotechnology and Genetic Engineering (Goril, J.N., and Kumar, P., Singh, V. K., eds.) Science Technology Publication, Studium Press, Houston, TX, USA, 4: 307-326.

24. Srivastava, S., Jain, R., Gupta, P. S. \& Singh, J. (2006). Genetic stability of in vitro raised Sugarcane plantlets by RAPD markers Plant. Cell Biotechnol. Molecul. Biol., 7 (1): 93-96.

25. Venkatachalam, L., Sreedhar R.V. \& Bhagyalakshmi, N. (2007). Genetic analysis of micropropagated and regenerated plantlets of banana as assessed by RAPD and ISSR markers. In Vitro Cell. Dev. Biol., 43: 267-274. 